\title{
Laparoscopic Resection of a Colonic Venous Malformation in an Infant
}

\author{
Thomas Lehnert, MD, Roland Boehm, MD, Steffi Mayer, MD, Ina Sorge, MD, \\ Thomas Richter, MD, PhD, Holger Till, MD, PhD \\ Department of Pediatric Surgery, University Hospital of Leipzig, Leipzig, Germany (Drs. Lehnert, Boehm, Mayer, Till). \\ Department of Pediatric Radiology, University Hospital of Leipzig, Leipzig, Germany (Dr. Sorge). \\ Department of Pediatrics, Hospital St. Georg, Leipzig, Germany (Dr. Richter). \\ Department of Pediatric and Adolescent Surgery, Medical University of Graz, Austria (Dr. Till).
}

\begin{abstract}
Introduction: Venous malformations in the bowel are extremely rare in children. A few case reports recommend the laparoscopic assisted mobilization of the lesion and conversion to an external resection and anastomosis. However, in infants with large tumors of the descending and sigmoid colon, this strategy would require a laparotomy.

Case Description/Technique Description: A 2-year-old girl presented with painless rectal bleeding and anemia. Ultrasonography and magnetic resonance imaging (MRI) revealed a $5 \times 3 \times 3$-cm angiodysplastic lesion of the distal bowel. Colonoscopy verified a vascular malformation of the sigmoid with exophytic growth. Performing a 4-port laparoscopy $(3-5 \mathrm{~mm})$, we identified the lesion along with grossly distended blood vessels in the sigmoid colon. After hitching it to the anterior abdominal wall, we carefully mobilized the lesion. To avoid a laparotomy of equivalent size or significant bleeding during externalization, the mass was resected laparoscopically using the LigaSure device (Covidien, Mansfield, Massachusetts). Finally an all-in laparoscopic anastomosis was fashioned (4-0 Vicryl, interrupted stitches; Ethicon, Somerville, New Jersey). The inspection of both remaining colonic margins showed no macroscopic evidence of the disease. The specimen was placed in a bag and morcellated with forceps through one slightly extended port site until it could be extracted. Operative time was 269 minutes. Histology described a venous malformation. The postoperative course was uneventful, and after a follow-up of more than 1.5 years, the girl remains free of symptoms.
\end{abstract}

Conclusion: An all-in laparoscopic resection of a vascular malformation of the colon can be performed successfully and with excellent cosmetic results in children and even infants.

Key Words: Laparoscopy, colonic resection, venous malformation, infant, child.

Citation Lehnert T, Boehm R, Mayer S, Sorge I, Richter T, Holger T. Laparoscopic resection of a colonic venous malformation in an infant. CRSLS e2014.00057. DOI 10.4293/CRSLS.2014.00057.

Copyright (C) 2014 SLS This is an open-access article distributed under the terms of the Creative Commons Attribution-Noncommercial-ShareAlike 3.0 Unported license, which permits unrestricted noncommercial use, distribution, and reproduction in any medium, provided the original author and source are credited.

Address correspondence to: Holger Till, MD, PhD, Department of Pediatric and Adolescent Surgery, Medical University of Graz, Auenbruggerplatz 34 , 8036 Graz, Austria. E-mail: holger.till@medunigraz.at Phone: +43-316-385-13762

\section{INTRODUCTION}

The question of whether laparoscopic bowel resections for colonic lesions in children can be performed completely intracorporeally (all-in) rather than laparoscopically assisted with an external anastomosis remains to be answered. To address this question, we present the case of a 2-year-old girl with a vascular mass in the sigmoid colon and outline our technical approach together with the midterm outcome.

\section{CASE REPORT}

The patient presented with painless rectal bleeding after blunt abdominal trauma with a bicycle. Her previous medical history was uneventful. The clinical examination was normal, with no evidence of a syndrome or cutaneous vascular malformations. Cardiologic assessment was uneventful. Blood results showed impaired values of transaminases and blood coagulation. Microbiological and virological smear tests of stool were negative. Abdominal 
ultrasonography and magnetic resonance imaging (MRI) scan revealed a $5 \times 3 \times 3$-cm angiodysplastic lesion of the distal bowel (Figure 1). Colonoscopy depicted a vascular malformation $20 \mathrm{~cm}$ proximal of the anus with exophytic growth (Figure 2).

For preoperative bowel management, osmotically active laxatives were administered. During diagnostic laparoscopy, the mass was identified in the sigmoid colon with grossly distended vessels (Figure 3). In a 4-port technique (3-5 mm), two hitch stitches (3-0 Prolene, Ethicon, Somerville, New Jersey) were placed in the colon descendens/sigmoideum and were placed adjacent to the lesion for elevation, complete assessment, and circumferential mobilization of the lesion. To avoid a laparotomy for externalization or intraluminal bleeding due to compression, the lesion was resected applying the LigaSure device (Covidien, Mansfield, Massachusetts). The inspection of both remaining colonic margins showed no remaining evidence of the disease. Thus, an all-in laparoscopic single-row anastomosis using interrupted stitches (4-0 Vicryl, Ethicon) was performed (Figure 4). The specimen was placed in a bag and morcellated with forceps through one slightly extended port site until it could be extracted piece by piece. Operative time was 269 minutes. Histology described a cavernous, mainly venous, partially thrombosed cavity, coated with endothelium. The postoperative course was uneventful, and after a follow-up of

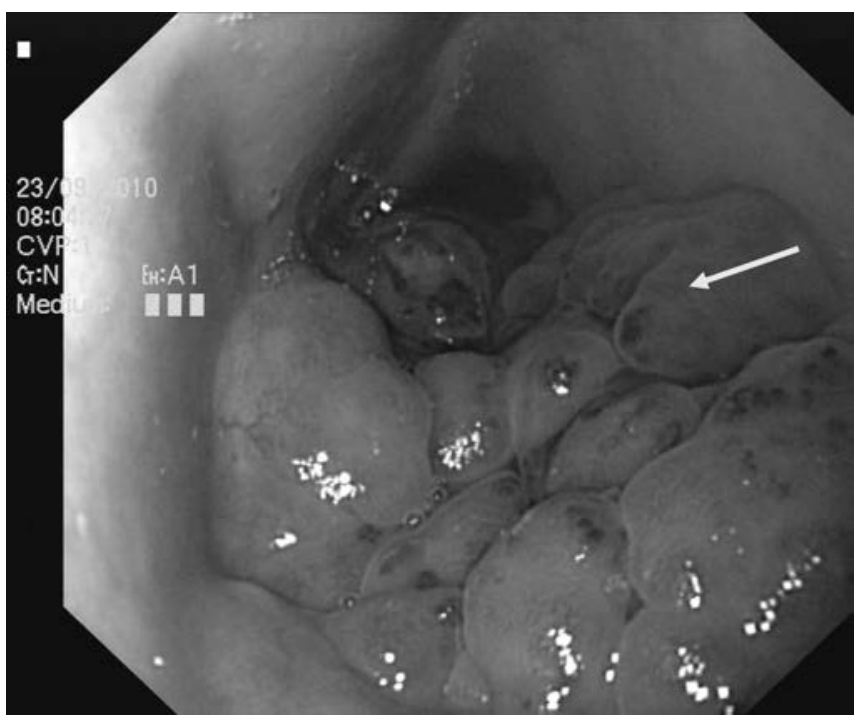

Figure 2. Colonoscopy showing on exophytic vascular lesion inside the sigmoid colon.

more than 1.5 years, the girl is free of symptoms with cosmetically appealing cicatricial conditions (Figure 5).

\section{DISCUSSION}

Vascular masses of the gastrointestinal tract in children are extremely rare and remain a therapeutic challenge. ${ }^{1}$ In

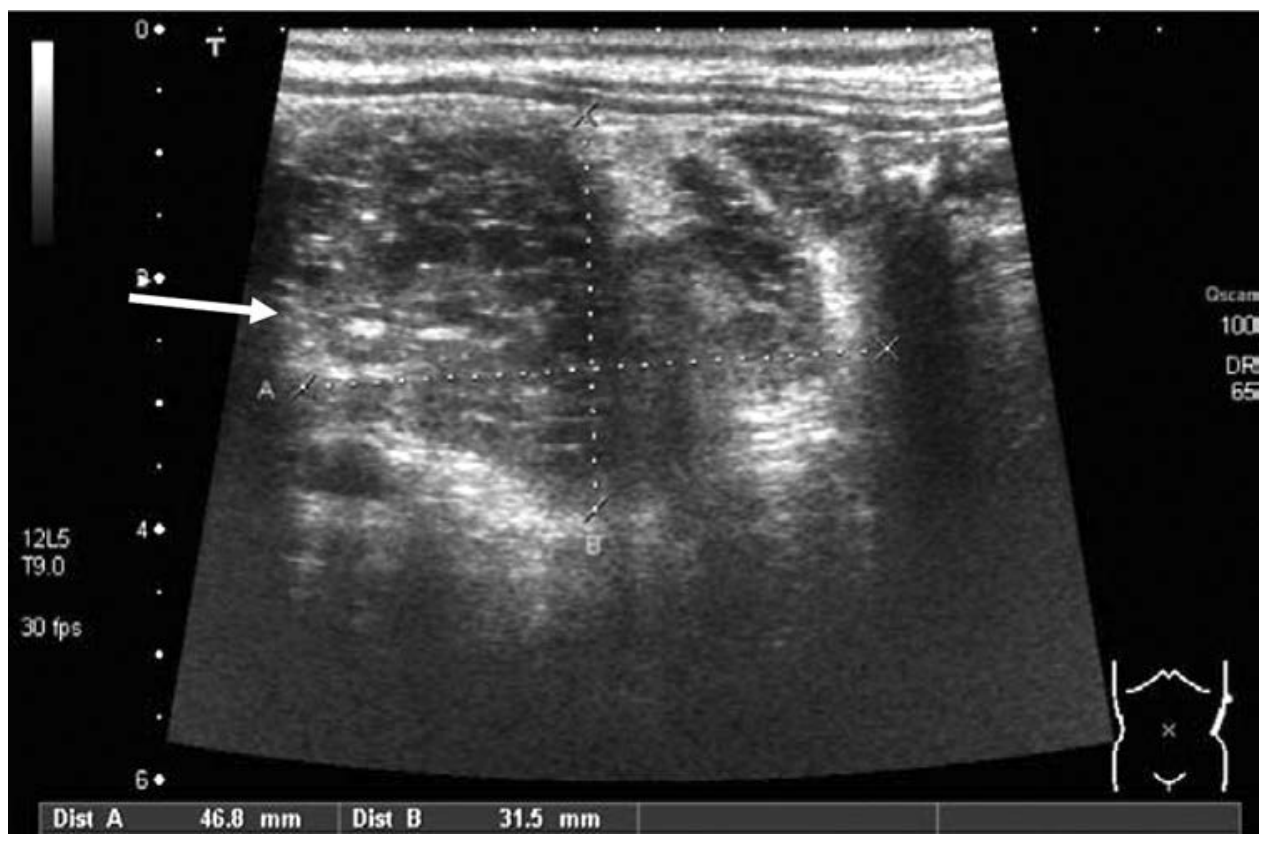

Figure 1. Abdominal sonography of a multy-cystic, low-flow lesion $(5 \times 3 \mathrm{~cm})$. 


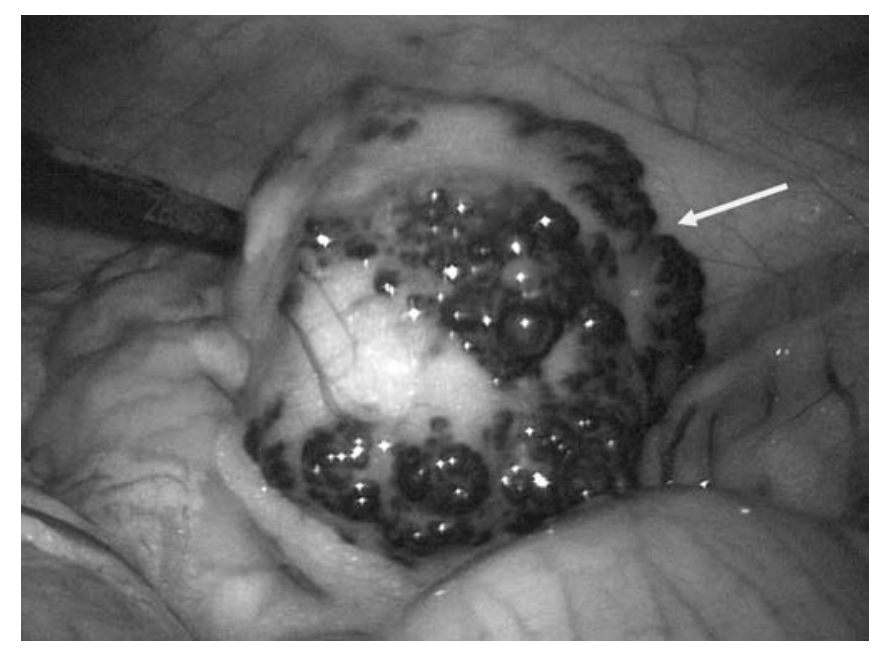

Figure 3. Laparoscopic identification of the vascular malformation with circumscript margins in the sigmoid colon.

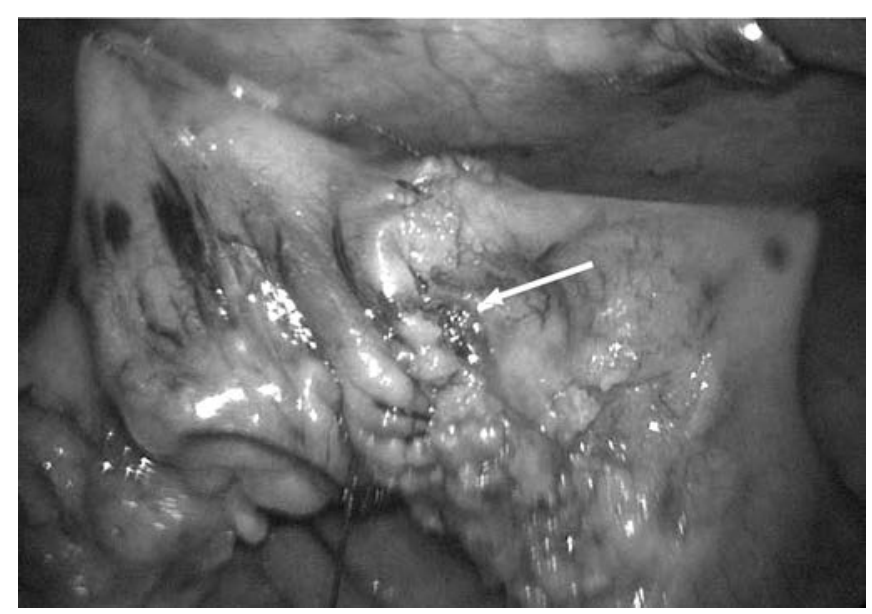

Figure 4. All-in laparoscopic bowel anastomosis.

principle, Mulliken and Glowacki in 1982 differentiated between hemangiomas and vascular malformations due to a distinct difference in the proliferative capacity of children's endothelia. ${ }^{2}$ The term hemangiomatosis describes the presence of multiple cutaneous hemangioma and potential visceral lesions. This diagnosis must not be confused with blue rubber bleb nevus syndrome, characterized by cutaneous and gastrointestinal vascular malformations. ${ }^{3}$ Ultrasonographic examinations and MRI scans may distinguish the dynamic character of hemangiomas from the static flow pattern in vascular malformation. Additionally, MRI scan appears as an appropriate imaging technique to investigate multiple locations of the disease in one session. ${ }^{4}$

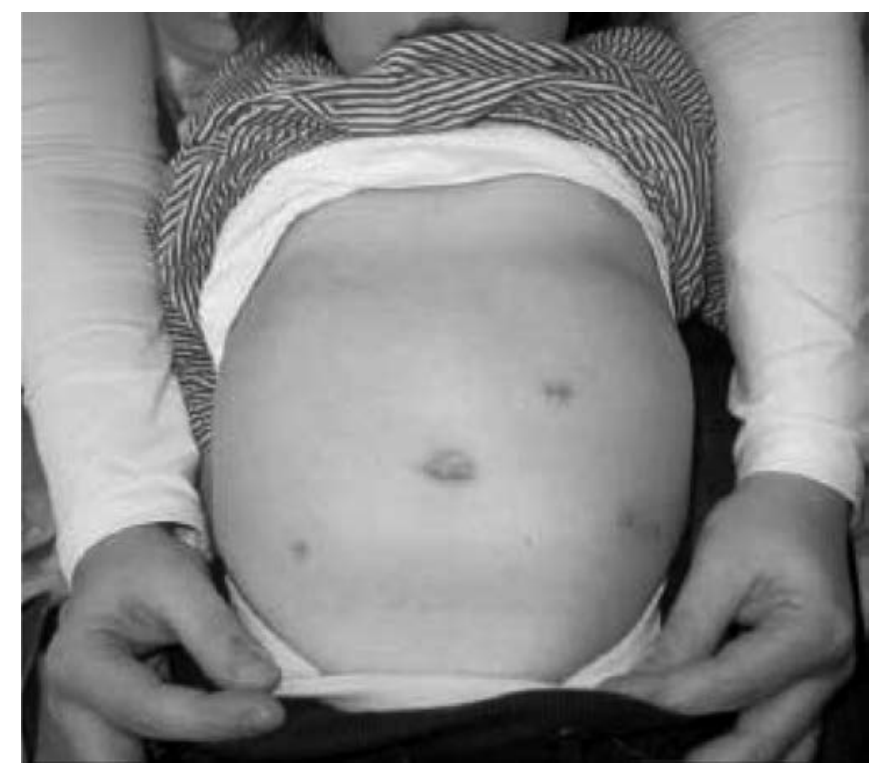

Figure 5. Cosmetic results after laparoscopic bowel resection (note that the incision in the left lower quadrant served for specimen retrieval.)

In the present case, both diagnostic investigations were not absolutely conclusive, probably due to an almost complete thrombosis. Consequently, a colonoscopy was undertaken that allowed for an immediate and clear diagnosis, as well as a distinct assessment of its extent, followed by an immediate planning of adequate therapy.

In general, hemangioma can be treated by a variety of techniques like laser coagulation, scleropathy, or even ligation. However, vascular malformations of the bowel are extremely rare and require surgical resection, especially when they cause significant bleeding and anemia, as in the present case. In 2005, Aziz et $\mathrm{al}^{5}$ presented a patient with vascular malformation of the small bowel treated by a combined laparoscopic and open approach. The small bowel hosting the mass was resected, and a primary ileoileostomy was performed. For colonic manifestations, various strategies have been described in the literature, such as colectomies, mucosectomies or transanal resections. Recently, Fernandez-Pineda ${ }^{6}$ advocated a minimally invasive approach for colonic location. Similarly, Simon et $\mathrm{al}^{7}$ concluded that laparoscopic intestinal surgery could be performed in children and adolescents with a satisfactory operation time, low conversion rate, and low morbidity. However, whether the final resection and anastomosis should be performed truly laparoscopically as an all-in technique, or should rather be externalized through the umbilicus, remains a matter of debate. The major arguments for the latter approach seem to be safety and op- 
erative time. On the contrary, the wound needs to be extended depending on the size of the lesion, and consequently the surgical trauma may be increased considerably. Moreover, each manipulation of the vascular malformation or compression during externalization could cause considerable intra- and extraluminal bleeding. Thus, minimal handling during laparoscopic resection and an all-in laparoscopic anastomosis could increase safety and decrease surgical trauma. Nevertheless, laparoscopic bowel surgery with an all-in anastomosis represents a technical challenge in this age-group and requires defined surgical skills.

In conclusion, an all-in laparoscopic resection of a venous malformation of the colon in children can be performed successfully and with excellent cosmetic results.

\section{References:}

1. Sylla P, Deutsch G, Luo J, et al. Cavernous, arteriovenous, and mixed hemangioma-lymphangioma of the rectosigmoid: rare causes of rectal bleeding-case series and review of the literature. Int J Colorectal Dis. 2008;23(7):653-658.
2. Mulliken JB, Glowacki JG. Hemangiomas and vascular malformations in infants and children: a classification based on endothelial characteristics. Plast Reconstr Surg. 1982;69:412-422.

3. Agnese M, Cipolletta L, Bianco MA, Quitadamo P, Miele E, Staiano A. Blue rubber bleb nevus syndrome. Acta Paediatr. 2010; 99(4):632-635.

4. Mechri M, Soyer P, Boudiaf M, Duchat F, Hamzi L, Rymer R. Small bowel involvement in blue rubber bleb nevus syndrome: MR imaging features. Abdom Imaging. 2009;34(4): $448-451$.

5. Aziz A, Kane TD, Meza MP, Vaughan KG, Hackam DJ. An unusual cause of rectal bleeding and intestinal obstruction in a child with peripheral vascular malformations. Pediatr Surg Int. 2005;21:491-493.

6. Fernandez-Pineda I. Vascular tumors and malformations of the colon. World J Gastroenterol. 2009;15(41):5242-5243.

7. Simon T, Orangio G, Ambroze W, Schertzer M, Armstrong D. Laparoscopic bowel resection in children. Dis Colon Rectum. 2003;46(10):1325-1331. 